Gynecologic and

Obstetric Investigation
Received: July 11, 2018

Accepted after revision: November 11, 2018

Published online: January 11, 2019

\title{
Morphological and Functional Changes in the Vagina following Critical Lifespan Events in the Ewe
}

\author{
Lucie Hympanova $^{a-c}$ Rita Rynkevic ${ }^{a, b}$ e Iva Urbankova ${ }^{a-c}$ Silvia Blacher ${ }^{f}$ \\ Laurent de Landsheere $^{\mathrm{g}}$ Katerina Mackova ${ }^{\mathrm{a}-\mathrm{c}}$ Ladislav Krofta $^{c}$ Jan Deprest ${ }^{\mathrm{a}, \mathrm{b}, \mathrm{d}}$ \\ ${ }^{a}$ Centre for Surgical Technologies, KU Leuven, Leuven, Belgium; ${ }^{b}$ Department of Development and Regeneration, KU \\ Leuven, Leuven, Belgium; 'Institute for the Care of Mother and Child, Third Faculty of Medicine, Charles University, \\ Prague, Czech Republic; dPelvic Floor Unit, University Hospitals KU Leuven, Leuven, Belgium; eINEGI, Faculdade de \\ Engenharia da Universidade do Porto, Porto, Portugal; ${ }^{f}$ Laboratory of Tumor and Development Biology, GIGA-Cancer, \\ Institute of Pathology, University of Liège, Liège, Belgium; 9 Department of Obstetrics and Gynaecology, University of \\ Liège, Liège, Belgium
}

\section{Keywords}

Sheep - Vagina - Biomechanics - Genital tract - Delivery ·

Menopause $\cdot$ Reproduction

\begin{abstract}
Background/Aims: The ewe is increasingly being used as an animal model for pelvic floor disorders. The aim was to further characterize changes in the vaginal properties during its entire lifespan. Methods: Vaginal tissues were collected at different stages of reproductive life (neonatal, prepubescence, nulliparous, primiparous, multiparous, and menopausal; $\geq 6$ ewes/group). Vaginal size, as well as active and passive biomechanics, was measured. Microscopy included thickness of glycogen, epithelium, lamina propria and muscularis thickness, densities of collagen, elastin, smooth muscle, and nerves. Results: Vaginal dimensions increase during adolescence, peak at reproductive levels, and decrease sharply after ovariectomy. One year after first delivery, the distal vagina gets more compliant, yet this is reversed later in life. The thickness of glycogen staining epithelial layers changed with puberty and menopause. The epithelium was markedly thicker after multiple deliveries. The thickness of
\end{abstract}

lamina propria and muscularis increased in puberty and in nulliparous. Semi-quantitative collagen assessment demonstrated a lower collagen and higher elastin content after first and multiple deliveries. Conclusion: The changes in the ovine vaginal wall during representative moments of her lifespan parallel those observed in women.

(C) 2019 S. Karger AG, Basel

\section{Introduction}

Pelvic floor disorders (PFD) are caused by a combination of anatomical, physiological, genetic, reproductive, and lifestyle factors which interact throughout life. DeLancey et al. [1] proposed a lifespan model describing how these factors may compromise pelvic floor function and lead to symptoms. Roughly spoken, the pelvic floor reaches maximal functionality in the late teens. Rarely, genetically predisposed women have early onset PFD. During reproductive life, pregnancy and vaginal delivery are the first major inciting factor, yet most women recover from their symptoms. The second major inciting factor is age, which induces a continuous decline in pelvic floor

\section{KARGER}

() 2019 S. Karger AG, Basel 
function. Menopause may add to this. Additional interfering factors may boost the development of PFD, amongst which obesity is probably the most relevant one.

Researchers use, amongst other tools, animal models to study pelvic floor function in physiological as well as pathophysiologic conditions. These models are also useful for preclinical testing of interventions meant to reverse the natural course of PFD [2-4]. Animal models have the advantage that one can characterize features which are difficult to obtain clinically as well as one can do longitudinal studies. Rodents have a relatively small pelvic floor limiting their use, as there might not be sufficient tissue for comprehensive testing, neither are some measurements possible given the small specimen size. Rabbits have also been used, and though their vagina is larger, the histologic structure is not well comparable to that of humans [5]. Also the dimensions are relatively small [6]. Non-human primates are closest to humans [79], however, their use in research has been nearly completely banned in Europe [10]. Sheep may be alternatives as their pelvic floor anatomy and dimensions as well as the microscopic architecture have many similarities to that of humans $[11,12]$. We and others have recently become interested in sheep for pelvic floor research and experimental surgery [13-15]. For that purpose, we previously compared the pelvic floor anatomy and tissue composition of reproductive, pregnant, and postpartum ewes to that of women $[11,12,16-18]$. Herein, we further explore the impact of key moments in the lifespan of women on the ovine pelvic floor, using gross anatomical and biomechanical readouts.

\section{Materials and Methods}

\section{Animals}

Thirty-eight swifter ewes were included in this study: (1) neonatal (day 1 of life, $n=6$ /group), (2) prepubescent (age: 0.3 years, $n=6$ /group), (3) early reproductive yet nulliparous (age: 1 year, $n=6$ /group), (4) 1 year after first vaginal delivery (age: 2 years, $n$ =6/group), (5) multiparous (age: 7 years, $n=6$ /group), (6) menopausal (age: 7 years, exceptionally $n=8$ /group). The cycle of reproductive sheep was synchronized by insertion of a medroxy-progesterone acetate sponge (Veramix, Pfizer, IJsel, The Netherlands) for 14 days and were euthanized 5 days after its removal [17]. Not many species have a spontaneous and lasting menopause. Most other mammalians, including sheep, have lifelong estrous cycles and typically are removed from the life stock when not reproducing anymore [19]. We surgically induced menopause by ovariectomy [20]. In that group, we recruited a higher number of animals $(n=8)$, to compensate for potential loss of animals. All survived and were euthanized 160 days later. The age and weight of animals are displayed in Figure 1.
All animals were treated in accordance with current national guidelines on animal welfare. The experiment was approved by the Ethics Committee for Animal Experimentation of the Faculty of Medicine of the K.U. Leuven. Some animals were redundant from another experiment. Neonatal lambs were fraternal twins from an experiment on the co-twin.

\section{Explantation and Macroscopy}

Following euthanasia, the vagina with surrounding tissue and organs were first harvested en bloc. The vagina was dissected and cut longitudinally along the line of urethral insertion. First, the length and width were measured [17] and the vagina was divided into a distal, middle, and proximal part. Active biomechanical properties were tested immediately after explantation on $4 \times 8 \mathrm{~mm}$ specimens. Passive biomechanical testing by ball-burst testing was done on $35 \times 35 \mathrm{~mm}$ specimens. The proximal part includes the vaginal fornices and was not tested because of its inappropriate shape and size. In neonatal lambs, the specimen was too small for passive biomechanical testing. In all groups, $1 \times 1 \mathrm{~cm}$ specimens of the distal and middle vagina were fixed in paraformaldehyde for histology.

\section{Biomechanical Testing}

Active biomechanical testing was done on freshly harvested explants. The weight of the distal resp. middle vaginal sample was measured using a FZ-300i balance (A\&D, Tokyo, Japan; measurement accuracy: $0.001 \mathrm{~g}$ ). Both strips were oriented along the circumferential axis of the vagina and placed into warmed $\left(37^{\circ} \mathrm{C}\right)$ physiological Krebs solution with $\mathrm{CO}_{2} / \mathrm{O}_{2}$. Samples were twice subjected to a $0.5 \mathrm{mN}$ preload and allowed to equilibrate for $1 \mathrm{~h}$. After $1 \mathrm{~h}$, each sample was subjected to stepwise increasing doses of potassium (15-120 mM KCl). The contractile force was normalized to the tissue weight $(\mathrm{mN} / \mathrm{g})$.

Specimens for passive biomechanics were frozen $\left(-20^{\circ} \mathrm{C}\right)$ in a saline soaked gauze. When collection of specimens was complete, they were thawed $6 \mathrm{~h}$ prior testing. Thickness was measured prior to clamping using a micrometer (Mitutoyo, Kawasaki, Japan, accuracy $0.01 \mathrm{~mm}$ ). A Zwick tensiometer (Zwick GmbH \& Co. KG, Ulm, Germany) with a 200-N load cell was used with an $11.5 \mathrm{~mm}$ plunger, and $\varnothing 30 \mathrm{~mm}$ compression ring with an aperture of $\varnothing 20$ $\mathrm{mm}$. Specimens were preloaded $(0.1 \mathrm{~N})$ and loaded under $10 \mathrm{~mm} /$ min speed till disruption. TestXpert II software (Zwick GmbH \& Co) was used to record measurements. The stiffness $(\mathrm{N} / \mathrm{mm})$ in the comfort (lower forces) and stress (higher forces) zone were calculated [21].

\section{Histology and Immunohistochemistry}

Five $\mu \mathrm{m}$ tissue sections were stained by Hematoxylin and Eosin, periodic acid-Schiff for presence of glycogen Masson's trichrome for connective tissue with predominance of collagen, Miller's pentachrome for elastin, alpha smooth muscle antibodies (clone 1A4, 1:200 dilution DAKO) for smooth muscle, and PGP9.5 (Abcam, Cambridge, UK) for neurons. The exact protocols we used were earlier reported in detail elsewhere [22]. Thickness of the epithelium, lamina propria, and muscularis were measured with ZEN2 lite software (Carl Zeiss Microscopy, Oberkochen, Germany 2011) on an Axioplan 40 microscope (Zeiss). Full slide digitalized images were acquired with the fully automated digital microscopy system dotSlide (Olympus, BX51TF, Aartselaar, Belgium) coupled with a Peltier-cooled high-resolution digital color camera $(1,376 \times 1,032$ 
Basic characteristics

\begin{tabular}{|l|c|c|c|c|c|c|}
\hline & Neonat & Prepub & Nullip & Primip & Multip & Menop \\
\hline Age, year & 0 & 0.3 & 1 & 3 & 7 & 7 \\
\hline Weight, kg & 3.7 & 24 & 50 & 57 & 67 & 58 \\
\hline$n$ (per group) & 6 & 6 & 6 & 6 & 6 & 8 \\
\hline
\end{tabular}

a

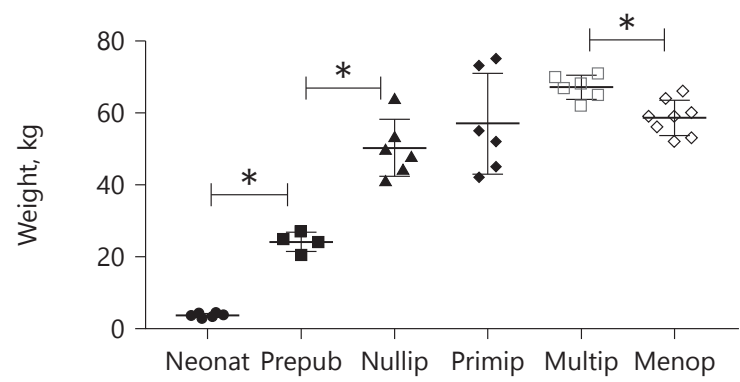

Biomechanics

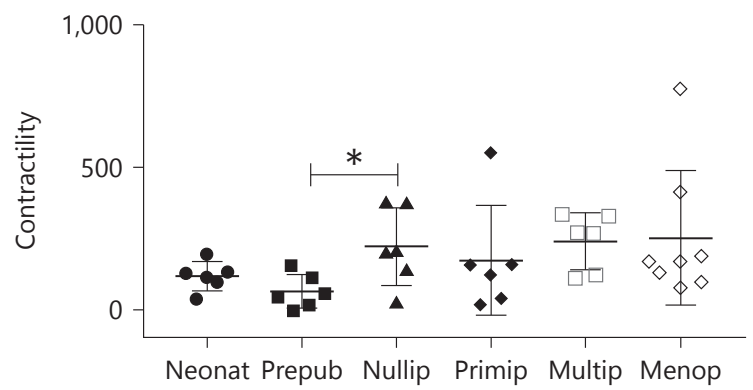

e

Distal vagina

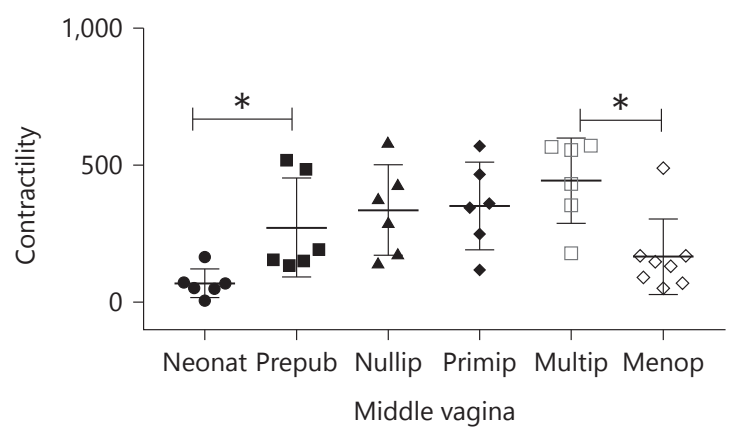

Fig. 1. a Sheep characteristics. $\mathbf{b}$ Change of weight and $(\mathbf{c}, \mathbf{d})$ vaginal dimensions during different life periods of ewe. $\mathbf{e}$ and $\mathbf{f}$ Active contractility and $(\mathbf{g}, \mathbf{h})$ stiffness at comfort zone of specimens at differ-

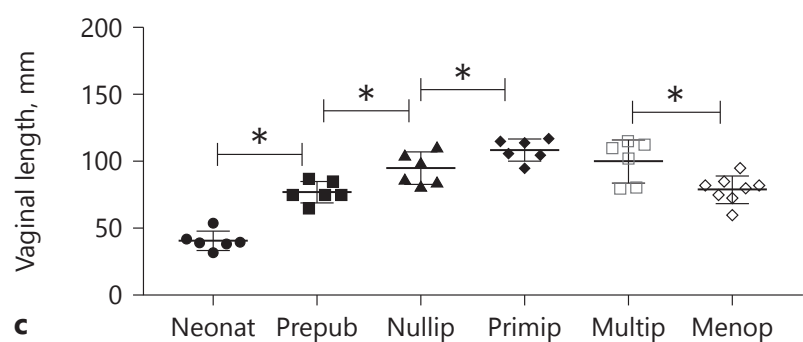

C

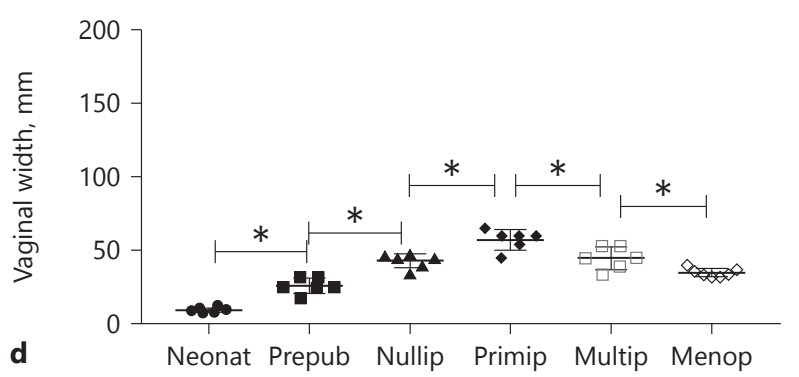

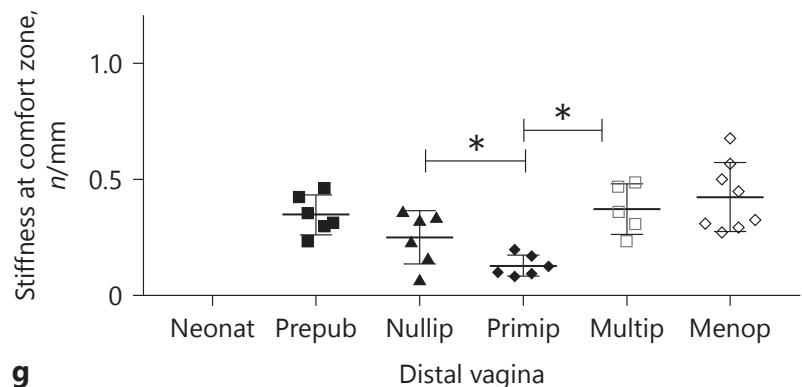

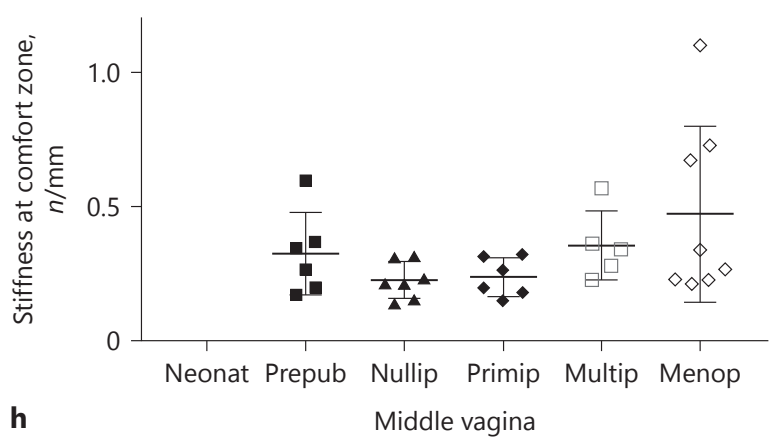

ent lifespan periods. Neonat - neonatal, Prepub - prepubescent, Nullip - nulliparous, Primip - 1 year after first vaginal delivery, Multip - multiple deliveries, Menop - 160 day after ovariectomy. 
Table 1. Table summaries all values from quantitative analysis

\begin{tabular}{|c|c|c|c|c|c|c|}
\hline Distal vagina & Neonatal & Prepubescent & Nulliparous & Primiparous & Multiparous & Menopausal \\
\hline \multicolumn{7}{|l|}{ Stiffness, $n / \mathrm{mm}$} \\
\hline Comfort zone & - & $0.35 \pm 0.09$ & $0.25 \pm 0.12^{*}$ & $0.13 \pm 0.05^{*, \#}$ & $0.37 \pm 0.10^{\#}$ & $0.42 \pm 0.15$ \\
\hline Stress zone & - & $9.33 \pm 2.44$ & $9.36 \pm 4.62$ & $7.14 \pm 3.40$ & $9.30 \pm 1.63$ & $7.45 \pm 2.64$ \\
\hline Contractility & $116.90 \pm 51.22$ & $63.44 \pm 59.25^{*}$ & $222.30 \pm 136.60 *$ & $99.15 \pm 65.69$ & $239.10 \pm 99.19$ & $167.8 \pm 41.91^{\dagger}$ \\
\hline \multicolumn{7}{|l|}{ Thickness, $\mu \mathrm{m}$} \\
\hline Glycogen & $10.96 \pm 6.80$ & $5.12 \pm 2.97$ & $29.55 \pm 8.89$ & $29.07 \pm 8.21$ & $27.24 \pm 10.91$ & $2.76 \pm 1.21$ \\
\hline Epithelium & $47.79 \pm 10.35$ & $48.31 \pm 27.70$ & $44.52 \pm 8.12$ & $40.03 \pm 12.07^{*}$ & $101.10 \pm 31.23 *, \#$ & $37.2 \pm 10.08^{\#}$ \\
\hline Lamina propria & $190.30 \pm 63.11^{*}$ & $436.20 \pm 208.80^{*}$ & $468.80 \pm 162.40$ & $512.30 \pm 104.80$ & $503.40 \pm 94.14$ & $564.60 \pm 183.70$ \\
\hline Muscularis & $770.10 \pm 265.00^{*}$ & $1,652.00 \pm 599.00^{*, \#}$ & $3,682.00 \pm 1,384.00^{\#}$ & $2,503.00 \pm 367.70$ & $2,328.00 \pm 162.30$ & $2,167.00 \pm 675.60$ \\
\hline \multicolumn{7}{|l|}{ Densities } \\
\hline Collagen & $0.38 \pm 0.03$ & $0.48 \pm 0.08$ & $0.54 \pm 0.03^{*}$ & $0.38 \pm 0.05^{*, \#}$ & $0.45 \pm 0.05^{\#, \Delta}$ & $0.62 \pm 0.04^{\Delta}$ \\
\hline Elastin & $0.01 \pm 0.01$ & $0.02 \pm 0.02$ & $0.01 \pm 0.00^{*}$ & $0.05 \pm 0.03^{*}$ & $0.05 \pm 0.01^{\#}$ & $0.02 \pm 0.01^{\#}$ \\
\hline Smooth muscle & $0.18 \pm 0.04$ & $0.13 \pm 0.09$ & $0.17 \pm 0.04$ & $0.14 \pm 0.03$ & $0.14 \pm 0.02$ & $0.18 \pm 0.08$ \\
\hline Neuronal stain PGP 9.5 (\% area) & - & $0.80 \pm 0.36$ & $0.40 \pm 0.24$ & $0.57 \pm 0.32$ & $1.70 \pm 0.75$ & $0.46 \pm 0.28$ \\
\hline Middle vagina & Neonatal & Prepubescent & Nulliparous & Primiparous & Multiparous & Menopausal \\
\hline \multicolumn{7}{|l|}{ Stiffness, $n / \mathrm{mm}$} \\
\hline Comfort zone & $0.39 \pm 0.23$ & $0.32 \pm 0.15$ & $0.23 \pm 0.19$ & $0.24 \pm 0.07$ & $0.35 \pm 0.11$ & $0.30 \pm 0.12^{\dagger}$ \\
\hline Stress zone & $0.53 \pm 0.46$ & $13.37 \pm 5.95$ & $16.15 \pm 5.29$ & $18.63 \pm 1.63^{*}$ & $10.53 \pm 4.31^{*}$ & $8.94 \pm 2.67^{\dagger}$ \\
\hline Contractility & $69.97 \pm 51.77^{*}$ & $173.70 \pm 73.35^{*, \dagger}$ & $337.60 \pm 1,649$ & $352.3 \pm 159.10$ & $444.70 \pm 156.60^{\#}$ & $119.40 \pm 48.52^{\#}$ \\
\hline \multicolumn{7}{|l|}{ Thickness, $\mu \mathrm{m}$} \\
\hline Glycogen & $4.68 \pm 4.63$ & $5.71 \pm 2.28$ & $36.82 \pm 19.66$ & $22.76 \pm 5.22$ & $20.94 \pm 7.60$ & $1.88 \pm 1.18$ \\
\hline Epithelium & $39.69 \pm 15.19$ & $41.05 \pm 25.27$ & $39.60 \pm 6.90$ & $32.55 \pm 10.11^{*}$ & $72.83 \pm 29.34^{*, \#}$ & $28.32 \pm 7.27^{\#}$ \\
\hline Lamina propria & $149.70 \pm 38.35^{*}$ & $400.40 \pm 80.46^{*, \#}$ & $782.20 \pm 275.60^{\#, \Delta}$ & $509.70 \pm 139.40^{\Delta}$ & $462.40 \pm 171.40$ & $420.20 \pm 106.80$ \\
\hline Muscularis & $547.90 \pm 271.80 *$ & $1,734.00 \pm 533.70^{*, \#}$ & $2,664.00 \pm 634.50^{\#}$ & $1,970.00 \pm 519.50$ & $2,212.00 \pm 396.00$ & $2,044.00 \pm 478.50$ \\
\hline \multicolumn{7}{|l|}{ Densities } \\
\hline Collagen & $0.45 \pm 0.09 *$ & $0.56 \pm 0.05^{*}$ & $0.45 \pm 0.16$ & $0.39 \pm 0.03$ & $0.43 \pm 0.09^{\#}$ & $0.62 \pm 0.07^{\#}$ \\
\hline Elastin & $0.01 \pm 0.01$ & $0.01 \pm 0.01$ & $0.01 \pm 0.01^{*}$ & $0.04 \pm 0.02 *, \#$ & $0.07 \pm 0.02^{\#, \Delta}$ & $0.02 \pm 0.01^{\Delta}$ \\
\hline Smooth muscle & $0.18 \pm 0.06$ & $0.16 \pm 0.04$ & $0.15 \pm 0.07$ & $0.12 \pm 0.01$ & $0.14 \pm 0.04$ & $0.20 \pm 0.70$ \\
\hline Neuronal stain PGP 9.5 (\% area) & - & $0.65 \pm 0.30$ & $0.50 \pm 0.37$ & $0.76 \pm 0.32$ & $1.74 \pm 0.84$ & $0.74 \pm 0.35$ \\
\hline Vaginal length & $40.7 \pm 7.2^{*}$ & $77.0 \pm 8.0^{*}, \#$ & $95.0 \pm 12.0^{\#, \Delta}$ & $108.7 \pm 8.3^{\Delta}$ & $100.2 \pm 15.9^{+}$ & $79.0 \pm 10.2^{+}$ \\
\hline Vaginal width & $9.8 \pm 1.6^{*}$ & $26.2 \pm 5.3^{*}, \#$ & $43.2 \pm 4.8^{\#, \Delta}$ & $57.3 \pm 7.0^{\Delta,+}$ & $44.8 \pm 7.5^{+, \phi}$ & $34.9 \pm 2.9^{\phi}$ \\
\hline Ewe weight & $3.7 \pm 0.4^{*}$ & $24.1 \pm 2.7^{*}, \#$ & $50.2 \pm 8.0^{\#}$ & $57.0 \pm 14.0$ & $67.5 \pm 4.1^{\Delta}$ & $58.1 \pm 4.8^{\Delta}$ \\
\hline
\end{tabular}

Values followed by the same character $(\Delta,+, *, \#, \phi)$ are significantly different $(p<0.05)$. Not normally distributed data are marked by ${ }^{\dagger}$.

pixels; XC10, Olympus) at high magnification (100×) resulting in virtual images in which the pixel size was $0.65 \mu \mathrm{m}$.

Image processing and measurements were performed using the image analysis toolbox of MATLAB R2016a (9.0.0.341360; Mathworks, Inc., Natick, MA, USA) according to a methodology described previously [23]. On the binary images, we measured the collagen, elastin, and smooth muscle density (area occupied by stain of interest per unit surface). For evaluation of the lamina propria neuronal network, 10 sections stained for PGP9.5 were manually analyzed for the presence of nerves.

\section{Statistics}

Normality testing was done by the Shapiro-Wilk test. Comparison of groups with normally distributed data was performed with $t$ test and Mann-Whitney for non-normally distributed data. We compared groups chronologically before and after start of reproductive life, before and after first delivery, the latter compared to findings after $\geq 4$ deliveries, and those multiparous to menopausal. Neonatal data are displayed for completeness. According to normality, data were reported as mean \pm SD or median \pm SEM. Significance level was defined as $p<0.05$.

\section{Results}

Demographics of the animals as well as biomechanical outcomes are displayed in Figure 1. All measured values (macroscopy, biomechanics, histology) including data from neonatal animals are displayed in Table 1. Graphs with glycogen stain and epithelial thickness, collagen and elastin density together with representative figures of histology are in Figure 2. No differences in the latter were observed. We did not observe differences in smooth muscle density. Below we describe the changes happening through different phases of the lifespan of ewes.

\section{Prepubescent versus Early Reproductive Age}

While the animals were growing and their weight increased, the vagina also became longer and wider. The contractile force of the reproductive vagina was higher, without measurable change in stiffness. Morphologically 


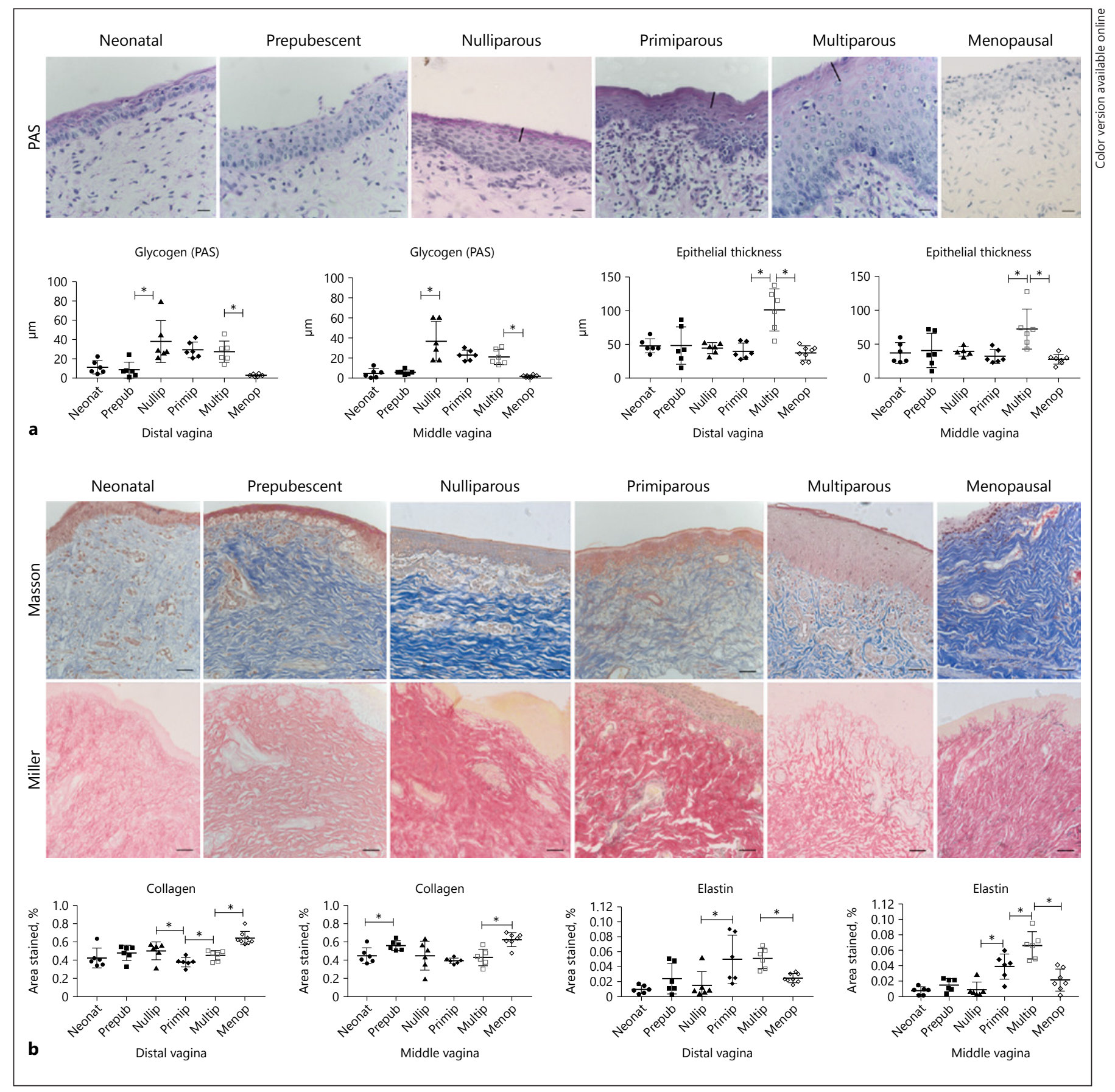

Fig. 2. a Representative figures of epithelial and glycogen (dark superficial purple layer marked by black line) thickness accompanied by graphs with results. b Representative figures of connective tissue in lamina propria. Blue on Masson's Trichrome stains mainly collagen. Black elastin fibers are visible on Miller stain, again accompanied with graphs. Neonat - neonatal, Prepub - prepubescent, Nullip - nulliparous, Primip - 1 year after first vaginal delivery, Multip - multiple deliveries, Menop - 160 day after ovariectomy. PAS, periodic acid-shiff. 
the superficially located glycogen containing layer of epithelial cells was thicker, yet the total thickness of the epithelial layer was similar. The lamina propria and muscularis were thicker, though the collagen and elastin density was comparable.

\section{Nulliparous versus Primiparous Ewes}

In primiparous ewes, the vagina was longer and wider. There was no measurable impact on vaginal contractility, yet the stiffness of the distal vagina was lower. In that area, the collagen density was lower and the elastin density higher. The thickness of the glycogen rich layer of the epithelium, of the epithelium, the lamina propria, and the muscularis was not different in nulliparous and primiparous ewes.

\section{Primiparous versus Multiparous Ewes}

In multiparous animals, the vagina became narrower. There was a discrepancy in findings in the distal and middle vagina. The distal vagina became stiffer. This coincided with an increased collagen density, yet no changes in elastin were observed. Its epithelium was also thicker; the glycogen rich layer was of equal thickness. There were no differences in the thickness of the lamina propria and muscularis. Vaginal contractility was neither different.

The middle vagina displayed similar collagen and an increased elastin content, no difference in stiffness and nor in contractility.

\section{Status after Ovariectomy in Multiparous Ewes}

Following ovariectomy the ewes weighed less and their vagina was shorter and narrower. The epithelial layer was thinner and there was less glycogen content. There was no change in vaginal laxity. However, the vaginal contractility in the middle vagina was lower. This coincided with a higher collagen and lower elastin density, yet similar thickness of the lamina propria or muscularis.

\section{Discussion}

In this study, we documented the changes of ovine vaginal properties at different scales throughout the lifespan of a ewe. The purpose was to make a parallel to what is known on the human vagina. In girls, the vagina is proportionally small, reaching $6 \mathrm{~cm}$ in length prior to puberty [24]. This dramatically changes when growing up, as it does in our sheep. In a large demographic study using clinical assessment with the pelvic organ prolapse (POP)-Q score, the vaginal length was correlated with biometry and age, and reached around $9.4 \mathrm{~cm}$ by adulthood. The vaginal size is apparently very comparable to what we measured in our ewes at reproductive age from this study, hence making the model representative from a surgical perspective. Exact dimensions reported in studies change according to the method used. Using vaginal casts, the vagina at reproductive age is $11.5 \mathrm{~cm}$ (measured to the end of fornix) and $4.7 \mathrm{~cm}$ wide [25]. When using MRI [26] the distance from the cervix to the introitus, excluding the fornix, is $6.3 \mathrm{~cm}$ and the width of the lumen in the proximal part is $3.3 \mathrm{~cm}$. In sheep, we measured an increase in vaginal dimensions with first delivery, both in length and width. The vaginal length was also increased in the above mentioned study using MRI [26], yet this was mainly because the fornices enlarged. We unfortunately did not measure that specifically in sheep; moreover, the transition from cervix to vagina is different in sheep [27]. Thereafter, in multiparous sheep, vaginal dimensions were smaller again, in particular the vagina became narrower. Also in women who get older, vaginal dimensions diminish $(-0.08 \mathrm{~cm}$ for every 10 years [age: $58.9 \pm 13.6$ year]). Clinically there is also an additional reduction by $0.17 \mathrm{~cm}$ around the menopause [28]. Shortening and narrowing of the vagina is clinically one of the typical clinical signs of vulvovaginal atrophy, yet most studies do not really provide values or measurements [29]. In sheep, the vaginal dimensions became smaller in artificially menopaused sheep. Our experiment however does not identify what changes would occur at elder age as our sheep were around 9 years maximum. Whereas these animals easily can become older, it is difficult to get hold of such ewes as they are usually removed from the stock.

Our knowledge about vaginal biomechanical properties in women is very limited, given that large specimens are not easily available. Recently, Eberhart et al. [30] reviewed the current knowledge on changes in selected patient groups and in animals. The clinical literature does not report much on the biomechanical properties of the vagina of asymptomatic women over the course of their life. The available data demonstrate that women with a high BMI or who are menopausal have a stiffer vaginal wall $[31,32]$. In our menopausal sheep, we also observed an increase in stiffness. Much more is known about the biomechanical characteristics of POP patients as compared to those without [30]. These are however inconsistent and we neither have really parallel data. Though the ewe has been suggested as a model mimicking spontaneous POP [33], it remains uncertain from what point one should consider the ovine vagina to be prolapsed.
$6 \quad$ Gynecol Obstet Invest DOI: $10.1159 / 000495348$
Hympanova/Rynkevic/Urbankova/Blacher/ de Landsheere/Mackova/Krofta/Deprest 
We also documented biomechanical changes following delivery. The laxity of the distal vagina increased after first vaginal delivery, which is in line with our previous study and with the study performed by Emmerson et al. $[17,34]$. In the sheep of this study, the distal vagina became stiffer after multiple deliveries. This finding is not in concordance with that of Emmerson et al. [34] yet in that study the animals were half the age (3-4 years) of that of our (4.5-9.5 years) sheep. To our knowledge, no robust clinical data on this matter are available.

We also documented the collagen content. There are clinical data on collagen content in the vaginal wall of women that is from patients who are symptomatic and have anatomical abnormalities. Again, the findings are very discordant between studies investigating POP [35, 36]. Other studies focus on the vagina of women with stress urinary incontinence [37] and on the impact of estrogen therapy on incontinence in postmenopausal women [38]. However, we did not find studies describing physiological changes during the lifespan of asymptomatic women. We came across one study comparing the collagen ratio and total collagen content in the vaginal wall of castrated sheep being compared to that of menopausal women - yet without comparable measurements in premenopausal subjects [12]. This is a comparison we cannot make. In our ewes, following a single vaginal delivery, the distal vaginal wall contained less collagen, as previously measured by hydroxyproline assay and reported by Emmerson et al. [34]. Thereafter, in multiparous and even more so after castration, the collagen density increased, the first already described in literature [34]. Our semi-quantitative findings in collagen parallel the changes in stiffness. Under the assumption that collagen I is the major constituent, and responsible for connective tissue stiffness, this makes sense [39]. One must however be cautious because the method we use for measuring collagen is semi-quantitative. Also the findings on elastin content parallel what was earlier described in ewes. Our primiparous ewes displayed an increased elastin density which is in agreement with observations of Emmerson et al. [34]. In multiparous ewes, the density increased in the middle vagina, a trend also observed in 2 other studies [34, 40]. Clinical observations we cannot really give, as the few studies on elastin in clinical vaginal specimens we are aware of, are in women with POP and urinary incontinence [35]. We have no explanation why the neuronal stain was comparable between groups. This may be due to the fact that in this species there is no difference, or that the measurement is not sensitive to detect it. PGP 9.5 stain was used to stain neuronal network in cadaveric human specimen observations [41] as well as in rhesus macaques [22].

Smooth muscle contractility is considered as a proxy for vaginal function [42]. Contractility of female vaginal tissue has been reported in few studies using various agents that can make smooth muscles contract (i.e., $\mathrm{KCl}$, carbachol, phenylephrine, others) [43-45]. However, all specimens have been obtained from elder gynecological patients (hysterectomy for benign lesions or malignancy, POP) and no comparison between comparable time points during life has been performed so far. In sheep vaginal contractility testing as we did, was used only in 2 studies investigating impact of delivery on vaginal contractility. These studies reported discordant results [17, 46]. Another study in which contractility was tested, did so for the purpose of documenting the impact of foreignmaterial implantation in pelvic floor reconstruction [47]. In our sheep, we saw an increase in contractility when the ewes became reproductive and a drop at menopause. We are not aware of studies by others in sheep, neither about parallel measurements in women without PFDs, yet during different stages of reproduction. The only data we know of are from women with POP and further from rats, in which contractility recovers 4 weeks after delivery [48]. Studies investigating the density of smooth muscle and the thickness of the lamina muscularis focus again mainly on women with POP. Those studies show concordant results, that is, a decrease in smooth musculature in POP patients [49]. We have not found studies describing changes over the course of life in women, few studies described the impact of deliveries on smooth muscle in ewes, however with discordant results [34, 40].

This study has several limitations. First the number of animals at each time point is limited. Second, it is not a longitudinal study, that is, in the same animals biopsied at different time points. Third, we did not have a standardized read out set for reporting. We could certainly have expanded the outcome measures such as clinical POP-Q score adapted to sheep, plasma estrogen levels, biochemical analysis of ECM components, or more advanced molecular analysis. We could also have done passive biomechanical testing with cyclic preconditioning. We did choose however not to do so because we wanted compare the results with our previous studies [17]. We also could have expanded our observations to other interesting phases during the lifespan of an ewe, such as pregnancy, different time points after vaginal delivery, following delivery via cesarean section or after sustained menopause ( $>1$ year). One could also focus on documenting 
the impact of estrus, synchronization, season, food intake, and other environmental impacts which may have an effect on the ewe [50]. In our previous study, we chose shorter period (60 days) after ovariectomy [51], which in that study yielded a measurable effect on the vaginal epithelium [17]. This time we wanted to determine whether the effects persist or even are more exacerbated by a longer menopausal period. One hundred and sixty days is what is found in the literature on research into osteoporosis [52-55], yet the observation period could be even longer. These shortcomings add to the limitation that there is at present, to our knowledge, no good reference literature on findings in humans at the time points in life as used in this study, making the full translation difficult. Indeed, our study provides insight on what changes different lifespan events induce in the sheep vagina. This is relevant data, now that sheep are increasingly being proposed as a large animal model of POP, usable for testing surgical procedures. Sheep have been frequently used in vaginal surgery training that is, vaginal hysterectomy or transvaginal meshes insertion $[56,57]$. The second approach was used also in reproductive medicine research to test novel implant materials that is, collagen coated or electrospun meshes $[13,15,58,59]$. Other methodologic strengths are that we used ball-burst testing which more closely represents the in vivo-biomechanical situation as compared to uniaxial testing, often used in the literature. The ECM histologic quantification was performed on the entire specimen, rather than selected regions, which is more often used [22,34].

Vaginal wall properties are influenced by different events occurring throughout life. Vaginal size and stiffness described in women were in parallel to our observations in sheep. Notably the vagina was stiffer in menopausal women as in our castrated animals. Other findings, not yet described in women, that is, collagen and elastin changes, were in agreement with earlier published data on sheep. Additionally in this study, in multiparous ewe, castration adversely affect vaginal contractility.

\section{Acknowledgement}

We thank Rosita Kinnart (Centre for Surgical Technologies, KU Leuven), Catherine Luyten, Petra Stevens (Department of Development and Regeneration, G-PURE laboratory, KU Leuven).

\section{Disclosure Statement}

The authors declare no conflicts of interest.

\section{References}

1 DeLancey JO, Kane Low L, Miller JM, Patel DA, Tumbarello JA: Graphic integration of causal factors of pelvic floor disorders: an integrated life span model. Am J Obstet Gynecol 2008;199:610.e1-e5.

2 Deprest J, Feola A: The need for preclinical research on pelvic floor reconstruction. BJOG 2013;120:141-143.

3 Abramowitch SD, Feola A, Jallah Z, Moalli PA: Tissue mechanics, animal models, and pelvic organ prolapse: a review. Eur J Obstet Gynecol Reprod Biol 2009;144(suppl 1):S146S158.

4 Feola A, Abramowitch S, Jallah Z, Stein S, Barone W, Palcsey S, Moalli P: Deterioration in biomechanical properties of the vagina following implantation of a high-stiffness prolapse mesh. BJOG 2013;120:224-232.

5 Barberini F, Correr S, De Santis F, Motta PM: The epithelium of the rabbit vagina: a microtopographical study by light, transmission and scanning electron microscopy. Arch Histol Cytol 1991;54:365-378.

6 Ozog Y, Mazza E, De Ridder D, Deprest J: Biomechanical effects of polyglecaprone fibers in a polypropylene mesh after abdominal and rectovaginal implantation in a rabbit. Int Urogynecol J 2012;23:1397-1402.
7 Coates KW, Gibson S, Williams LE, Brady A, Abee CR, Shull BL, Kuehl TJ: The squirrel monkey as an animal model of pelvic relaxation: an evaluation of a large breeding colony. Am J Obstet Gynecol 1995;173:1664-1670.

8 Otto LN, Slayden OD, Clark AL, Brenner RM: The rhesus macaque as an animal model for pelvic organ prolapse. Am J Obstet Gynecol 2002;186:416-421.

9 Schimpf M, Tulikangas P: Evolution of the female pelvis and relationships to pelvic organ prolapse. Int Urogynecol J Pelvic Floor Dysfunct 2005; 16:315-320.

10 (SCHER) SC on H ER: Non-human primates in research and safety testing. 2009.

11 Urbankova I, Vdoviakova K, Rynkevic R, Sindhwani N, Deprest D, Feola A, Herijgers P, Krofta L, Deprest J: Comparative anatomy of the ovine and female pelvis. Gynecol Obstet Invest 2017;82:582-591.

12 Ulrich D, Edwards SL, Letouzey V, Su K, White JF, Rosamilia A, Gargett CE, Werkmeister JA: Regional variation in tissue composition and biomechanical properties of postmenopausal ovine and human vagina. PLoS One 2014;9:e104972.

13 Feola A, Endo M, Urbankova I, Vlacil J, Deprest T, Bettin S, Klosterhalfen B, Deprest
J: Host reaction to vaginally inserted collagen containing polypropylene implants in sheep. Am J Obstet Gynecol 2015;212:474. e1-e8.

14 Urbankova I, Callewaert G, Sindhwani N, Turri A, Hympanova L, Feola A, Deprest J: Transvaginal mesh insertion in the ovine model. J Vis Exp 2017.

15 Manodoro S, Endo M, Uvin P, Albersen M, Vláčil J, Engels A, Schmidt B, De Ridder D, Feola A, Deprest J: Graft-related complications and biaxial tensiometry following experimental vaginal implantation of flat mesh of variable dimensions. BJOG 2013;120:244250.

16 Ulrich D, Edwards SL, Su K, White JF, Ramshaw JA, Jenkin G, Deprest J, Rosamilia A, Werkmeister JA, Gargett CE: Influence of reproductive status on tissue composition and biomechanical properties of ovine vagina. PLoS One 2014;9:e93172.

17 Urbankova I, Callewaert G, Blacher S, Deprest D, Hympanova L, Feola A, De Landsheere L, Deprest J: First delivery and ovariectomy affect biomechanical and structural properties of the vagina in the ovine model. Int Urogynecol J 2018, DOI: 10.1007/s00192-0173535-9. 
18 Ulrich D, Edwards SL, Alexander DLJ, Rosamilia A, Werkmeister JA, Gargett CE, Letouzey $\mathrm{V}$ : Changes in pelvic organ prolapse mesh mechanical properties following implantation in rats. Am J Obstet Gynecol 2016; 214:260.e1-260.e8.

19 Reinwald S, Burr D: Review of nonprimate, large animal models for osteoporosis research. J BONE Miner Res 2008;23:1353-1368.

20 Peiró JR, Nogueira GM, Nogueira GP, Perri $\mathrm{SH}$, Cardoso D: Ovariectomy by left flank approach in prepubertal Nelore (bos indicus) heifers. Can J Vet Res 2009;73:237-240.

21 Ozog Y, Konstantinovic ML, Werbrouck E, De Ridder D, Edoardo M, Deprest J: Shrinkage and biomechanical evaluation of lightweight synthetics in a rabbit model for primary fascial repair. Int Urogynecol J 2011;22: 1099-1108.

22 Jallah Z, Liang R, Feola A, Barone W, Palcsey S, Abramowitch SD, Yoshimura N, Moalli P: The impact of prolapse mesh on vaginal smooth muscle structure and function. BJOG 2016;123:1076-1085.

23 De Landsheere L, Blacher S, Munaut C, Nusgens B, Rubod C, Noel A, Foidart JM, Cosson $\mathrm{M}$, Nisolle M: Changes in elastin density in different locations of the vaginal wall in women with pelvic organ prolapse. Int Urogynecol J 2014;25:1673-1681.

24 Eyk NV, Allen L, Giesbrecht E, Jamieson MA, Kives S, Morris M, Ornstein M, Fleming N: Pediatric vulvovaginal disorders: a diagnostic approach and review of the literature. J Obstet Gynaecol Can 2009;31:850-862.

25 Pendergrass L, Reeves CA, Belovicz MW, Molter DJ, White JH: The shape and dimensions of the human vagina as seen in threedimensional vinyl polysiloxane casts. Gynecol Obstet Invest 1996;42:178-182.

26 Barnhart KT, Izquierdo A, Pretorius ES, Shera DM, Shabbout M, Shaunik A: Baseline dimensions of the human vagina. Hum Reprod 2006;21:1618-1622.

27 Kershaw CM, Khalid M, McGowan MR, Ingram K, Leethongdee S, Wax G, Scaramuzzi RJ: The anatomy of the sheep cervix and its influence on the transcervical passage of an inseminating pipette into the uterine lumen. Theriogenology 2005;64:1225-1235.

28 Tan JS, Lukacz ES, Menefee SA, Luber KM, Albo ME, Nager CW: Determinants of vaginal length. Am J Obstet Gynecol 2006;195: 1846-1850.

29 Gandhi J, Chen A, Dagur G, Suh Y, Smith N, Cali B, Khan SA: Genitourinary syndrome of menopause: an overview of clinical manifestations, pathophysiology, etiology, evaluation, and management. Am J Obstet Gynecol 2016;215:704-711.

30 Eberhart R, Chuong C, Zimmern P: Exploring biomechanical methods to study the human vaginal wall. Neurourol Urodyn 2017;36: 499-506.

31 Lopez SO, Eberhart RC, Zimmern PE, Chuong CJ: Influence of body mass index on the biomechanical properties of the human pro- lapsed anterior vaginal wall. Int Urogynecol J 2015;26:519-525.

32 Goh JT: Biomechanical properties of prolapsed vaginal tissue in pre- and postmenopausal women. Int Urogynecol J Pelvic Floor Dysfunct 2002;13:76-79.

33 Young N, Rosamilia A, Arkwright J, Lee J, Davies-Tuck M, Melendez J, Werkmeister J, Gargett CE: Vaginal wall weakness in parous ewes: a potential preclinical model of pelvic organ prolapse. Int Urogynecol J 2017;28:999-1004.

34 Emmerson S, Young N, Rosamilia A, Parkinson L, Edwards SL, Vashi AV, Davies-Tuck M, White J, Elgass K, Lo C, Arkwright J, Werkmeister JA, Gargett CE: Ovine multiparity is associated with diminished vaginal muscularis, increased elastic fibres and vaginal wall weakness: Implication for pelvic organ prolapse. Sci Rep 2017;7:45709.

35 De Landsheere L, Munaut C, Nusgens B, Maillard C, Rubod C, Nisolle M, Cosson M, Foidart JM: Histology of the vaginal wall in women with pelvic organ prolapse: a literature review. Int Urogynecol J 2013;24:2011-2020.

36 Vetuschi A, D’Alfonso A, Sferra R, Zanelli D, Pompili S, Patacchiola F, Gaudio E, Carta G: Changes in muscularis propria of anterior vaginal wall in women with pelvic organ prolapse. Eur J Histochem 2016;60:2604.

37 Kerkhof MH, Ruiz-Zapata AM, Bril H, Bleeker MC, Belien JA, Stoop R, Helder MN: Changes in tissue composition of the vaginal wall of premenopausal women with prolapse. Am J Obstet Gynecol 2013;210:168.e1-e9.

38 Jackson S, James M, Abrams P: The effect of oestradiol on vaginal collagen metabolism in postmenopausal women with genuine stress incontinence. BJOG 2002;109:339-344.

39 Fratzl P: Collagen: Structure and Mechanics. Boston, Springer, 2008.

40 Rynkevic R, Martins P, Hympanova L, Almeida H, Fernandes AA, Deprest J: Biomechanical and morphological properties of the multiparous ovine vagina and effect of subsequent pregnancy. J Biomech 2017;57:94-102.

41 Song YB, Hwang K, Kim DJ, Han SH: Innervation of vagina: Microdissection and immunohistochemical study. J Sex Marital Ther 2009;35:144-153.

42 Traish AM, Botchevar E, Kim NN: Biochemical factors modulating female genital sexual arousal physiology. J Sex Med 2010;7:2925-2946.

43 Basha M, Labelle EF, Northington GM, Wang T, Wein AJ, Chacko S, Ückert S, Ehlers V, Nüser V, Oelke M, Kauffels W, Scheller, F, Jonas U: Functional significance of muscarinic receptor expression within the proximal and distal rat vagina. Am J Physiol Regul Integr Comp Physiol 2009;297:R1486-R1493.

44 Northington GM, Basha M, Arya LA, Wein AJ, Chacko S: Contractile response of human anterior vaginal muscularis in women with and without pelvic organ prolapse. Reprod Sci 2011;18:296-303.

45 Uckert S, Ehlers V, Nüser V, Oelke M, Kauffels W, Scheller F, Jonas U: In vitro functional responses of isolated human vaginal tissue to selective phosphodiesterase inhibitors. World J Urol 2005;23:398-404.

46 Jallah ZC. Moalli PA, Abramowitch SD: Vaginal delivery disrupts vaginal smooth muscle (VaSM) contraction. IEEE 2012:127-128.

47 Endo M, Urbankova I, Vlacil J, Sengupta S, Deprest T, Klosterhalfen B, Feola A, Deprest $\mathrm{J}$ : Cross-linked xenogenic collagen implantation in the sheep model for vaginal surgery. Gynecol Surg 2015;12:113-122.

48 Feola A, Moalli P, Alperin M, Duerr R, Gandley RE, Abramowitch S: Impact of pregnancy and vaginal delivery on the passive and active mechanics of the rat vagina. Ann Biomed Eng 2011;39:549-558.

49 Boreham MK, Wai CY, Miller RT, Schaffer JI, Word RA: Morphometric analysis of smooth muscle in the anterior vaginal wall of women with pelvic organ prolapse. Am J Obstet Gynecol 2002;187:56-63.

50 Mustonen E, Taponen S, Andersson M, Sukura A, Katila T, Taponen J: Fertility and growth of nulliparous ewes after feeding red clover silage with high phyto-oestrogen concentrations. Animal 2014;8:1699-1705.

51 Barron AM, Cake M, Verdile G, Martins RN: Ovariectomy and 17 beta-estradiol replacement do not alter beta-amyloid levels in sheep brain. Endocrinology 2009;150:3228-3236.

52 Turner A, Mallinckrodt C, Alvis M, Bryant H: Dual-energy X-ray absorptiometry in sheep: experiences with in vivo and ex vivo studies. Bone 1995;17(4 suppl):S381-S387.

53 Oheim R, Amling M, Ignatius A, Pogoda $\mathrm{P}$ : Large animal model for osteoporosis in humans: the ewe. EurCell Mater 2012;24:372-385.

54 MacLeay JM, Olson JD, Enns RM, Les CM, Toth CA, Wheeler DL, Turner AS: Dietaryinduced metabolic acidosis decreases bone mineral density in mature ovariectomized ewes. Calcif Tissue Int 2004;75:431-437.

55 Sigrist IM, Gerhardt C, Alini M, Schneider E, Egermann M: The long-term effects of ovariectomy on bone metabolism in sheep. J Bone Miner Metab 2007;25:28-35.

56 Kerbage Y, Giraudet G, Rubod C, Garabedian C, Rivaux G, Cosson M: Feasibility and benefits of the ewe as a model for vaginal surgery training. Int Urogynecol J 2017;28:1573-1577.

57 Mansoor A, Curinier S, Campagne-Loiseau S, Platteeuw L, Jacquetin B, Rabischong B: Development of an ovine model for training in vaginal surgery for pelvic organ prolapse. Int Urogynecol J 2017;28:1595-1597.

58 De Tayrac R, Alves A, Thérin M: Collagencoated vs noncoated low-weight polypropylene meshes in a sheep model for vaginal surgery. a pilot study. Int Urogynecol J Pelvic Floor Dysfunct 2007;18:513-520.

59 Hympánová L, Rynkevic R, Román S, Mori da Cunha MGMC, Mazza E, Zündel M, Urbánková I, Gallego MR, Vange J, Callewaert G, Chapple C, MacNeil S, Deprest J: Assessment of electrospun and ultra-lightweight polypropylene meshes in the sheep model for vaginal surgery. Eur Urol Focus 2018; pii: S2405-4569(18)30190-1. 